\title{
The perception of workload and task complexity and its influence on students' approaches to learning: a study in higher education
}

\author{
Eva Kyndt • Filip Dochy • Katrien Struyven • \\ Eduardo Cascallar
}

Received: 7 June 2010 /Revised: 23 November 2010

(C) Instituto Superior de Psicologia Aplicada, Lisboa, Portugal and Springer Science+Business Media BV 2010

\begin{abstract}
Researchers have tried to induce a deeper approach to learning by means of student-centred learning environments. Findings did not always confirm the positive hypotheses. This has given rise to the question as to what the discouraging or encouraging factors are for inducing a deep approach to learning. The aim of this research study is to determine whether perceived workload and task complexity are discouraging or encouraging factors. In addition, these relationships will be investigated under different induced conditions which offer the potential to deepen our understanding of the nature of the investigated relationships. Participants were 128 second year Bachelor level students in educational sciences. After an introduction with the theory, students were given four tasks with various workloads and task complexities after which they filled out questionnaires on learning approaches, perceived workload and perceived task complexity. For every task, correlations and multiple stepwise regressions were calculated. The information from the interviews was used to support and illustrate the results of quantitative analyses. In general, results show no significant relationship between perceived workload and students' approaches to learning. For perceived task complexity, it was found that a perceived lack of information is a discouraging factor for inducing a deep learning approach. A lack of information consistently increases students' surface approaches to learning regardless of the induced workload and task complexity.
\end{abstract}

Keywords Approaches to learning · Perceived workload · Perceived task complexity · Higher education

Successful functioning in a continuously changing society demands more than a basic knowledge and understanding of a domain of study and specific learning methods such as problem-based learning or team learning (Decuyper et al. 2010; Gijbels 2007). Higher education has been criticised for not developing the competences specific for professional

E. Kyndt $(\bowtie) \cdot$ F. Dochy $\cdot$ K. Struyven $\cdot$ E. Cascallar

Centre for Research on Professional Learning and Development, Corporate Training and Lifelong Learning, Katholieke Universiteit Leuven, Dekenstraat 2, Box 3772, 3000 Leuven, Belgium e-mail: Eva.Kyndt@ped.kuleuven.be 
expertise in our society (Boyatzis et al. 2002; Neilsen 2000). In general, these generic competences can be described as critical thinking, an aptitude for self management, learning, reflective thinking and the ability to solve novel and complex problems (Kember et al. 1997; Segers et al. 2006; Tynjälä 1999). Although these are important aims of higher education today, it seems that graduates frequently lack these qualities (Kember et al. 1997). The abovementioned competences have been associated with what is called a deep approach to learning (Biggs 2001; Kember et al. 1997) and research has shown the importance of the teaching and learning environment for students' approaches to learning (e.g. Campbell et al. 2001; Kember 2004; Gijbels et al. 2008; Struyven et al. 2006; Wilson \& Fowler 2005).

An approach to learning does not only refer to the strategies adopted during learning. It also has a motivational component: the intention of the student (Biggs 2001; Entwistle 1991; Marton \& Säljö 1997). Learning approaches are not stable characteristics of the learner, they are determined by a "relation" between the learner and the context in which he operates. In general, two approaches to learning are predominant in the educational literature; a surface approach to learning and a deep approach to learning (Marton \& Säljö 1997). The surface approach is characterised by rote learning, a learning intention that is extrinsic to the real purpose of the task (Biggs 2001; Entwistle et al. 2001) and is related to lower quality outcomes of learning (Trigwell \& Prosser 1991). The deep approach to learning is based on an intrinsic interest in the task and focuses on the underlying meaning. The learning strategies used aim at understanding and creating meaning (Biggs 2001; Entwistle et al. 2001). The deep approach to learning generally results in high-quality learning outcomes (Trigwell \& Prosser 1991).

Researchers have tried to induce a deeper approach to learning by means of studentcentred learning environments, such as problem-based learning (PBL) and studentactivating teaching methods (e.g. Gijbels et al. 2005; Nijhuis et al. 2005; Struyven et al. 2006; Wilson \& Fowler 2005). Several studies confirm the positive influence of these student-centred learning environments on deep approaches to learning (e.g. Tiwari et al. 2006; Wilson \& Fowler 2005). But surprisingly, other studies have observed opposite effects, and in many cases results have shown increases in surface approaches (e.g. Gijbels et al. 2005; Nijhuis et al. 2005; Segers et al. 2006; Struyven et al. 2006). These findings have given rise to the question as to what the discouraging or encouraging factors could be for inducing a deep approach to learning by means of student-centred teaching methods. Prior research has indicated that variables such as workload, assessment, clear goals and feedback have an influence on students' (deep) approaches to learning and even more variables have been suggested as possibly encouraging or discouraging a deep approach to learning (Baeten et al. 2010). In this research study the focus will be on the influence of the perception of two variables: workload (Kember 2004) and task complexity (Perkins 1991) on students' approaches to learning.

\section{Workload and students' approaches to learning}

Because of the difficulty of determining a truly objective measure for workload, research has almost always measured the perception of the students with regard to their workload. Former research used to use "hours of work or study" as a measurement, but Kember (2004) stated that this is not a good measurement of workload because time is merely a component of what shapes the perceived workload of a student. Hart and Staveland (1988) defined several possible sources of perceived workload divided into two categories; the first 
category concerns the demands placed on the individual (mental, physical and temporal), while the second category focuses on the interaction of the task with the individual (effort, frustration and performance). Perceived workload manifests itself as feelings of pressure or stress (Kember 2004) that are placed upon students in terms of the demands of the syllabus and assessment tasks (Entwistle \& Ramsden 1983). Several empirical research studies have argued that a perceived excessive workload is positively associated with surface approaches to learning (Entwistle \& Ramsden 1983; Kember 2004; Nijhuis et al. 2005; Prosser \& Trigwell 1999; Ramsden 1992; Sand-Jecklin 2007; Segers et al. 2006; Struyven et al. 2006). Kember (2004) stated that a perceived excessive workload can have a tendency to encourage surface approaches to learning since students resort to short cuts and undesirable study approaches to cope with the perceived excessive demands (Kember 2004). Entwistle and Ramsden (1983) also found that a perceived heavy workload related to a reproduction orientation or to a surface approach. Other research has come to the conclusion that an appropriate workload does relate significantly positive to a deep approach to learning (e.g. Diseth et al. 2006; Lizzio et al. 2002; Wilson et al. 1997) and significantly negative to a surface approach to learning (Diseth et al. 2006; Wilson et al. 1997). Finally, Karangiannopoulou and Christodoulides (2005) did not find a significant relationship between approaches to learning and perceived workload. Based on these prior researches, it can be hypothesised that workload is a prohibiting factor when inducing a deep approach by means of student-centred learning environments. Research studies investigating these learning environments also propose the influence of workload as a possible explanation for their results. The Nijhuis et al. (2005) results indicate that students' negative perceptions of the high workload of the PBL environment have acted as a prohibiting factor for the expected positive influence of the PBL environment on students' deep learning strategies. The results concerning the negative influence of workload are in line with the findings of Ramsden (1992) and Prosser and Trigwell (1999). In interviews, students have also pointed out that a high workload is a problem associated with student-activating settings. They indicate that a high workload forces them to employ surface learning strategies (Segers et al. 2006; Struyven et al. 2006).

\section{Task complexity and students' approaches to learning}

Perkins (1991) states that a constructivist mode of instruction such as problem-based learning or student-activating instruction very often require students to cope with complex situations. He states that the gap between the entry behaviour of the students and what is demanded of them could be too great (Perkins 1991). However, there exists little consensus among researchers concerning the properties that make a task complex (Campbell 1988). Before we can answer any questions about task complexity, it is important to establish what is meant by task complexity. The word "complex" originates from the Latin word complexus which means "that which is woven together"; complexity is like a multidimensional web of interactions (Mennin 2007). Complexity is not synonymous with difficulty; a certain task can be difficult (e.g. the probability of solving the task correctly) without being complex, while other tasks are difficult because they are complex. On the other hand, a task of specified complexity may be difficult for one person but not for another (Braarud 2001; Campbell 1988). Perceived task complexity and objective task complexity are not identical but are strongly related (Campbell 1988; Mangos \& SteeleJohnson 2001; Maynard \& Hakel 1997). Perceived task complexity is a reaction to task characteristics that may be evoked for reasons other than the task characteristics themselves 
(Braarud 2001; Campbell 1988), such as familiarity with the task, assessed cognitive resources, availability of tools, time and information (Mangos \& Steele-Johnson 2001). Therefore it is important to consider the subjective task's complexity, the individual's perception of how complex the task is (Braarud 2001; Mangos \& Steele-Johnson 2001) when studying the influence of task complexity on human performance and behaviour. The examples of Glouberman and Zimmerman (2002) of what is called a simple, a complicated and a complex problem can be used as a starting point for defining task complexity. Solving a simple problem, for example, is like following a recipe. No particular expertise is required, cooking expertise can improve the result, but it is not essential to get a result. Launching a rocket is an example of a complicated problem. Formulae are necessary and critical and high levels of expertise are necessary for success. Notwithstanding, there is a high degree of certainty of outcome. Finally, raising a child is complex. Formulae only have a limited application. Raising one child provides experience, but is no insurance for success with the next. Expertise can contribute, but is neither necessary nor sufficient to assure success. Since every child is unique, an uncertainty of outcome remains (Glouberman \& Zimmerman 2002). A complex task can be seen as a task with multiple paths to a solution and multiple (not necessarily, but possibly equally valuable) solutions. Expertise can help but may not be sufficient and an uncertainty of outcome remains (Glouberman \& Zimmerman 2002; Haerem \& Rau 2007). In higher education, an example of a complex assignment is asking students to apply a theoretical model to practice. Theoretical models are rarely found as they are in practice, the student always has to choose between several likely correct outcomes which leaves him or her with an uncertainty about the solutions despite of the fact they might have studied the model very well.

Task complexity has been investigated in relation to performance (Campbell 1988; Haerem \& Rau 2007; Mangos \& Steele-Johnson 2001; Maynard \& Hakel 1997; Salthouse 1992; Szafran 2001). Research has identified a main effect of subjective task complexity on performance (Mangos \& Steele-Johnson 2001). Maynard and Hakel (1997) specified this relation as a negative one in that when subjective task complexity increases, the quality of performance decreases. To our knowledge, task complexity has not been taken into account in most of the research regarding approaches to learning. But former research has shown that approaches to learning are related to qualitative learning outcomes and the performance of students (Trigwell \& Prosser 1991). Moreover, the research study of Stahl et al. (2006) showed that students acknowledge task complexity and plan their goals and strategies accordingly. This research study wants to investigate if student approaches to learning are influenced by the way students perceive task complexity.

\section{Present study}

Research has shown that students' perceptions of a course can often differ considerably from the intentions of the curriculum designer or the expectations of the teacher (Argyris \& Schön 1978). In addition, it has also been widely argued that students' learning approaches are not only influenced by the context and the content, but primarily by the students' perceptions of the teaching and learning environment (Hounsell 1984; Prosser \& Trigwell 1999; Ramsden 1992; Sadlo \& Richardson 2003). Kember and Leung (1998) and Ramsden (1992) have proposed that we should take the students' perception of the curriculum elements into account, rather than an "objective" measure. As a consequence, this study has chosen to investigate the perceived workload and task complexity of the student and their relationship with approaches to learning. The choice for the specific independent variables 
lies in the origin of this research. This study was set up to examine whether specific factors could have had an encouraging or discouraging influence on the induction of a deep approach to learning by means of a student-centred learning environment such as problembased learning. Both task complexity and workload are variables that students associate with a student-centred learning environment (Perkins 1991; Struyven et al. 2006). Differences in perceived workload might have given rise to differences in student learning, with high levels of perceived workload leading to higher levels of surface approaches because students in a student-centred learning environment did not feel able to take the risk of investing time and effort in understanding due to time constraints. On the other hand, Perkins (1991) argues that one of the demands of constructivism that is placed on learners is cognitive complexity.

The research questions in this study are:

- What is the relationship between perceived workload and students' approaches to learning?

- What is the relationship between perceived task complexity and students' approaches to learning?

Hypotheses are that a deep approach to learning will relate negatively to perceived workload, while surface approaches to learning will relate positively to perceived workload. Concerning the relationship of students' approaches to learning with perceived task complexity, no hypotheses can be formulated since no prior research was found. Expectations, based on the research of Stahl et al. (2006) are that perceived task complexity will relate with students' approaches to learning. However, the direction of the relationship remains unclear. According to Perkins (1991), one could expect that a high task complexity would discourage the induction of a deep approach to learning, while the research study of Stahl et al. (2006) suggests that a more complex task requires deeper approaches. For task complexity, the relation will also be investigated under different conditions in order to deepen our understanding of the nature of the relationship with students' approaches to learning.

\section{Method}

Sample

Participants in this study were 128 university students enrolled in the second year of the Bachelor programme in educational sciences. There were 122 female and six male participants, a proportion which is representative for the population of educational science students. All students had comparable course and work experiences; after finishing secondary education, they completed the first year of the bachelor programme in educational sciences. Other than the occasional summer job, none of them had work experience. Students were between 18 and 21 years old, the majority of the students were 19 years $(64.8 \%)$.

\section{Design}

This study is conducted in an authentic educational context within the setting of the university course "Theory and Practice of Group Work". After an introduction with the theory in five lectures, students were given four tasks with various workloads and task 
complexities (research conditions). This different research conditions were implemented because, despite of the fact that a clear hypothesis can be formulated for the relationship of workload with students' approaches to learning, previous research suggests that differences in results exist between the different research studies investigating this relation (e.g. Karangiannopoulou \& Christodoulides 2005; Kember 2004; Diseth et al. 2006). Some studies found significant relations of perceived workload with a surface approach, others with a deep approach, others with both approaches and finally some with neither of the approaches. It could be that these differences are tied to the objective workload of the environment in which the study was conducted. Therefore, we will investigate in this research study the relation between perceived workload and students' approaches to learning under different induced conditions, in order to determine if the nature of the relationship remains the same or differs under different objective conditions.

To control the effect of gradually implemented conditions or cross-over effects on the one hand and the effect of the content on the other hand, the group was divided into two sub-groups, groups A and B. Each group received the same four assignments regarding content and type of task, but group A had a different order of research conditions than group B (see Table 1). Students were randomly assigned to groups A or B. After each assignment, students filled out the questionnaire on learning approaches, perceived workload and perceived task complexity concerning the assignment that was completed at that time.

\section{Assignments}

The assignments were constructed in collaboration with the lecturer and the teaching assistant of the course. The tasks were constructed during several meetings, until a full consensus was reached concerning the complexity and the workload of each task.

The assignment inducing a low workload and low task complexity was different for groups A and B. Group A was asked to make a table with the criteria for team effectiveness sorted by level (individual, team and organisation) based on two given texts. Group B had to give three examples of cooperative (teaching) methods, one for pre-school, one for primary school and one for secondary school.

Next, group A had to undertake an assignment that tried to involve a high workload but low task complexity. This group was asked to draw up an interview schedule based on a given text and examples of questions on the topic "Cognitive and Socio-cultural Perspectives on Team Learning". Following this, they had to interview a member of a professional team and summarise the outcomes of the interview in a paper. The high workload and low task complexity assignment for group B comprised an observation of a meeting of a professional team. Afterwards they were expected to answer ten specific and

Table 1 Assignments: conditions and content per group

\begin{tabular}{llllll}
\hline & Group A & & \multicolumn{2}{l}{ Group B } \\
\cline { 2 - 3 } \cline { 5 - 6 } Content & Workload & Task complexity & & Workload & Task complexity \\
\hline Team effectiveness & Low & Low & High & High \\
Cognitive and socio-cultural perspective & High & Low & Low & High \\
Shared mental model & Low & High & High & Low \\
Cooperative teaching methods & High & High & Low & Low \\
\hline
\end{tabular}


simple questions about the team on the topic of a shared mental model and to substantiate their answers with examples from their observation.

The assignment with a low workload and high task complexity for both groups was analysing a hypothetical (one page long) case describing the working together of a professional team. Group A had to determine and substantiate whether or not this team had a shared mental model. Students in group B had to analyse the case and determine and substantiate which perspective on team learning (cognitive or socio-cultural) applied the most to the given case.

Finally, the assignment that tried to involve a high workload and high task complexity for group A concerned cooperative teaching methods. They were expected to observe a cooperative teaching method, make an observational report and analyse their observation in order to be able to identify and substantiate which theoretical cooperative teaching method was the most similar to what they observed. Group B, in the high workload and high task complexity condition, had to draw up an interview schedule regarding team effectiveness, interview a member of a professional team and analyse the effectiveness of the team based on the interview and the theory.

\section{Manipulation checks}

Eight students that completed the course successfully during the previous academic year were asked to judge the assignments regarding their workload and task complexity. They were not informed of the conditions of each assignment. These judges confirmed the intended conditions. The intra-class coefficients average measure (inter-rater reliability coefficient) equalled $0.82(p<0.001)$. Extra suggestions made by these judges were taken into account when finalising the assignments.

When the students completed all four assignments, they were asked to order the assignments from high to low regarding workload and task complexity. Both task characteristics were evaluated separately, students were asked to rank the assignments twice; once for workload and once for task complexity. To compute an average ranking by all students, we awarded the assignment that was considered the one with the highest workload or task complexity four points and the one with lowest workload was awarded one point. The sum of all points for each assignment was used to make an average ranking of the assignments. The assignments with the two lowest total scores were considered low. The assignments with the two highest scores were considered high. The manipulations of the assignments of group B were perceived as they were induced (see Table 2). For group A the manipulation of workload was also successful. For task complexity students ranked the mixed assignments differently, the manipulation of task complexity of the first and last assignment was perceived as intended.

\section{Instruments}

The students' approaches to learning were measured by means of the Revised Two-Factor Study Process Questionnaire (R-SPQ-2F; Biggs et al. 2001). The R-SPQ-2F is a more refined version of Biggs' (1987) original Study Process Questionnaire. The R-SPQ-2F comprises 20 items, scored on a five-point Likert scale. It measures two types of approaches to learning on the part of the students: surface approaches and deep approaches. Biggs et al. (2001) calculated a CFI value of 0.992 and the SRMR value of 0.015 for this two-factor model. According to the recommendation by $\mathrm{Hu}$ and Bentler (1999), a CFI value greater than 0.95 and SRMR less than 0.08 is an indication of a relatively good fit between the hypothesised model and the observed data. In this study, a translated validated version in Dutch of the R-SPQ-2F was used (Stes et al. 2008), the validation of this translated version resulted into good reliabilities for both 
Table 2 Manipulation check: average perception of workload and task complexity

\begin{tabular}{|c|c|c|c|c|c|c|c|c|c|}
\hline \multicolumn{2}{|c|}{ Assignment } & \multicolumn{2}{|c|}{ Table } & \multicolumn{2}{|c|}{$\begin{array}{l}\text { Interview without } \\
\text { analysis }\end{array}$} & \multicolumn{2}{|l|}{ Case } & \multicolumn{2}{|c|}{$\begin{array}{l}\text { Observation and } \\
\text { analysis }\end{array}$} \\
\hline & & WL & $\mathrm{TC}$ & WL & $\mathrm{TC}$ & WL & $\mathrm{TC}$ & WL & $\mathrm{TC}$ \\
\hline \multirow[t]{4}{*}{ Group A } & Intended & Low & Low & High & Low & Low & High & High & High \\
\hline & Average & Low & Low & High & High & Low & Low & High & High \\
\hline & Total score & 103 & 112 & 204 & 196 & 117 & 145 & 219 & 187 \\
\hline & & \multicolumn{2}{|c|}{ Examples } & \multicolumn{2}{|l|}{ Case } & \multicolumn{2}{|c|}{$\begin{array}{l}\text { Specific questions } \\
\text { observation }\end{array}$} & \multicolumn{2}{|c|}{$\begin{array}{l}\text { Interview and } \\
\text { analysis }\end{array}$} \\
\hline \multirow[t]{3}{*}{ Group B } & Intended & Low & Low & High & Low & Low & High & High & High \\
\hline & Average & Low & Low & High & Low & Low & High & High & High \\
\hline & Total score & 69 & 86 & 167 & 138 & 150 & 171 & 244 & 235 \\
\hline
\end{tabular}

surface $(\alpha=0.84)$ and deep approach $(\alpha=0.82)$. The current study also shows good reliabilities for each measurement moment (see Table 3).

The perceived workload of the task was measured by means of an adapted version of the NASATLX questionnaire (Braarud 2001; Hart \& Staveland 1988). NASA-TLX is a subjective, post-hoc workload assessment tool. NASA-TLX contains six items measuring mental demands, physical demands, temporal demands, own performance, effort and frustration (Hart \& Staveland 1988) on 7-point Likert scale ranging from 1 = "very low" to 7 = "very high". In their study, Hart \& Staveland (1988) calculated a test-retest correlation of 0.83. This questionnaire was translated from English to Flemish, the participants' mother tongue, according to the guidelines of the International Test Commission (Hambleton 1994). This translated version of the questionnaire was explored in a small pilot study. In this pilot study 113 first year Bachelor students in educational sciences were asked to fill in the questionnaire after undertaking an exercise as part of the course "Didactics, Part 1: Learning and Instruction". An exploratory factor analysis with the maximum likelihood extraction was performed. Based on the scree plot, one factor was extracted that explained $40.13 \%$ of the variance. All items loaded significantly on this factor, loadings were between 0.531 and 0.782 , except for one item. This non-significant item asked "How successful

Table 3 Reliability R-SPQ-2F (Biggs et al. 2001)

\begin{tabular}{lll}
\hline Test & Approach & Reliability (Cronbach's $\alpha$ ) \\
\hline Low workload & Deep & 0.81 \\
Low task complexity & Surface & 0.77 \\
High workload & & 0.84 \\
Low task complexity & Deep & 0.80 \\
& Surface & 0.85 \\
Low workload & & 0.84 \\
High task complexity & Deep & \\
High workload & Surface & 0.85 \\
High task complexity & & 0.80 \\
\hline
\end{tabular}


were you in accomplishing what you were asked to do?" and had a loading of -0.123 . Dropping this performance question raised the reliability of the factor from $\alpha=0.697$ to $\alpha=0.808$. An overall item "I found it a heavy task" was added.

The perception of task complexity was measured by a newly developed questionnaire. The questionnaire was based on the literature concerning task complexity (Braarud 2001; Campbell 1988; Haerem \& Rau 2007; Mangos \& Steele-Johnson 2001; Maynard \& Hakel 1997; Mennin 2007; Salthouse 1992; Szafran 2001). The task complexity index (TCI) developed by Braarud (2001) was used as starting point for the construction of our questionnaire. The TCI was an inspiration because Braarud (2001) factor analysed the NASA-TLX together with his TCI and found that the items loaded different factors. This is also the goal in this research study. However, since the context of educational sciences differs substantially from the context of a nuclear power plant for which the TCI was developed (Braarud 2001), the items had to be thoroughly revised. The perceived task complexity questionnaire of this study contains items such as "There were multiple possible solutions" and "I have undertaken similar tasks in the past". The students were asked to mark, on a five-point Likert scale, the degree to which the statement applies to them, ranging from 1 = "Does not apply at all" to 5 = "It applies completely". The goal of the questionnaire was to determine if the students viewed the assignment as a complex one, i.e. it aimed to measure the subjective complexity of the task.

\section{Analyses}

Since the task complexity questionnaire was a newly developed instrument which was administered together with the workload questionnaire, an explorative factor analysis was performed on both questionnaires together in order to reduce the data and to find the underlying structure of these questionnaires. The data of the 128 participants in this research study was used to test the validity and reliability of the scales based on the questionnaires used. First, we checked whether the data were suited for this kind of analysis. We calculated the determinant of the correlation matrix in order to rule out extreme correlations between different variables, following the assumption of factor analysis that correlations among variables should be moderate. This determinant equals 0.0001 , meaning that there were no extreme correlations. A Kaiser-Meyer-Olkin measure of sampling adequacy of 0.83 and a Bartlett's test of sphericity with a significance of $p<0.001$, also confirmed that the data were suitable for factor analysis.

Four factors were selected based on the eigenvalues criterion which explained $67.91 \%$ of the variance. The used extraction method was maximum likelihood. The first factor explained $33.77 \%$ of the variance $(\alpha=0.89)$ and contained all the items of the workload questionnaire plus three items of the task complexity questionnaire, asking how difficult and how complicated the assignment was, and how insecure they feel about their solution. This first factor was entitled "perceived workload". However, it should be noticed that apparently the perceptions of workload and difficulty were not entirely separated by the students. The distinction Nijhuis et al. (2008) made between the quantitative workload (for example a lot of literature to go through) and the quality of the work (such as a difficult case) seems to apply here. The perceived workload factor seems to measure both aspects of workload. This was unexpected because when creating the different workload conditions, we wanted to avoid an overlap with task complexity and therefore focused on the quantitative aspect of workload. High workload assignments were operationalised as assignments where a lot of time had to be invested and more output (in terms of pages for example) was required. The second factor focused on the 
"familiarity" of the student with the type of assignment and explained $13.35 \%$ of the variance $(\alpha=0.96)$. The third factor asked if there were multiple (correct) ways of coming to a solution, the explained variance amounting to $11.14 \%(\alpha=0.84)$. We will refer to this variable as "solutions". The final factor entitled "lack of information" explains $9.65 \%$ of the variance $(\alpha=0.71)$ and contained statements about the availability of information and its accessibility to complete the assignment. The factors "familiarity", "solutions" and "lack of information" represented different aspects of task complexity. Items and factor loadings can be found in Appendix 1.

In order to be able to proceed with the analysis, we had to check if there was a significant difference between groups $\mathrm{A}$ and $\mathrm{B}$ regarding approaches to learning under every research condition. When the group effect is ruled out, we can analyse the groups as if they were one group, otherwise the groups will have to be analysed separately. An ANOVA analysis was performed for every induced condition. Only the surface approach when attempting to induce a low workload and low task complexity differed significantly for groups A and B, with group B scoring higher than group A $(F(1,126)=$ $6.221, p<0.05)$. This is the only approach that had to be analysed separately for groups $\mathrm{A}$ and $\mathrm{B}$.

To determine the relationship between perceived workload and students' approaches to learning and perceived task complexity and approaches to learning within each condition for the entire group of students, correlations were calculated between students' approaches to learning and the four factors of perceived workload, familiarity, solutions and lack of information. A multiple stepwise linear regression was used for each condition separately to determine the relationship between the independent variables of perceived workload, familiarity, solutions and lack of information and the dependent variable of approaches to learning.

Additionally, individual and focus group interviews were conducted. In total, 15 students were interviewed. There were five individual interviews with students from groups A and B respectively. The focus group was created from five randomly selected students. During these interviews the aim was to discuss the experiences and perceptions of the students with regard to the course, the assignments and their learning approaches. These semi-structured interviews were audio-taped and transcribed. The information from the interviews was used to support and illustrate the results of quantitative analysis.

\section{Results}

The research questions in this study will be investigated within every induced research condition. The first research question focuses on the relationship between perceived workload and students' approaches to learning. Secondly, the relationship between perceived task complexity and students' approaches to learning will be discussed. After presenting the results for every induced research condition separately, the results across the several induced research conditions will be discussed. The results of the linear stepwise regression analyses will be presented in this section. Correlations are provided for your information and can be found in Appendix 2.

\section{High workload-high task complexity}

The first research question focuses on the relation between perceived workload and students' approaches to learning. In this research condition no evidence was found for this 
relationship. Perceived workload was excluded from the regression model when predicting a deep approach to learning $(\beta \operatorname{In}=0.029, t=0.335, p=0.738)$. The regression model that predicted the surface approach in this condition also excluded perceived workload $(\beta$ In $=-0.074, t=-0.834, p=0.406$ ). The significant predictors in these analyses were aspect of task complexity and will be discussed next, since the relation between task complexity and students' approaches to learning is the subject of our second research question.

In this research study, perceived task complexity is represented by three factors: multiple solutions, familiarity and a lack of information. Results show that a deep approach to learning is significantly negatively related with a lack of information and positively related with familiarity (see Table 4). The third factor "solutions" was excluded from the model ( $\beta$ $\mathrm{In}=0.077, t=-0.891, p=0.375)$. When predicting a surface approach to learning the stepwise regression excludes the factors familiarity $(\beta \mathrm{In}=-0.067, t=-0.755, p=0.452)$ and solutions $(\beta \mathrm{In}=-0.071, t=-0.800, p=0.425)$ from the model. A lack of information is the only significant predictor of a surface approach to learning (see Table 5) and relates positively to a surface approach.

\section{High workload-low task complexity}

In this high workload and low task complexity condition, the results also do not confirm the hypothesised negative relation between a deep approach to learning and perceived workload. Perceived workload is not a significant predictor of a deep approach to learning ( $\beta$ In $=0.096, t=1.085, p=0.280$ ). It also does not significantly predict a surface approach to learning $(\beta$ In $=-0.038, t=-0.434, p=0.665)$.

The relation between task complexity and students' approaches to learning that was found in the above described condition is partially confirmed in this condition. A deep approach to learning does not relate significantly to either of the three factors representing task complexity; familiarity $(\beta \mathrm{In}=0.058, t=0.649, p=0.518)$, solutions $(\beta \mathrm{In}=0.059, t=$ $0.669, p=0.505)$ and a lack of information $(\beta \operatorname{In}=-0.087, t=-0.984, p=0.327)$ are all excluded from the regression model. For the surface approach to learning the results of this condition do confirm the results of the high-high condition. A lack of information is a significant positive predictor for a surface approach to learning (see Table 6). The model of the stepwise regression excludes familiarity $(\beta \operatorname{In}=0.150, t=1.756, p=0.082)$ and solutions $(\beta \mathrm{In}=0.094, t=1.089, p=0.278)$ when predicting a surface approach to learning.

Low workload-high task complexity

The results concerning the relation between perceived workload and students' approaches to learning do not confirm our hypothesis, but they also do not confirm the results of the

Table 4 High workload-high task complexity condition: stepwise regression for deep approach to learning

\begin{tabular}{lllllll}
\hline Model & \multicolumn{2}{l}{$\begin{array}{l}\text { Unstandardised } \\
\text { coefficients }\end{array}$} & $\begin{array}{l}\text { Standardised } \\
\text { coefficients }\end{array}$ & $t$ & Sig. \\
\cline { 2 - 4 } & $\mathrm{B}$ & $\mathrm{Se}$ & $\beta$ & & & \\
\hline $\begin{array}{l}\text { Lack of } \\
\text { information } \\
\text { Familiarity }\end{array}$ & -0.194 & 0.062 & -0.273 & & -3.148 & 0.002 \\
\hline
\end{tabular}


E. Kyndt et al.

Table 5 High workload-high task complexity condition: stepwise regression for surface approach to learning

\begin{tabular}{lllllll}
\hline Model & $\begin{array}{l}\text { Unstandardised } \\
\text { coefficients }\end{array}$ & $\begin{array}{l}\text { Standardised } \\
\text { coefficients }\end{array}$ & $t$ & Sig. \\
\cline { 2 - 4 } & $\mathrm{B}$ & $\mathrm{Se}$ & $\beta$ & & \\
\hline $\begin{array}{l}\text { Lack of } \\
\text { information }\end{array}$ & 0.139 & 0.059 & 0.207 & 39.300 & 0.000 \\
\hline
\end{tabular}

other research conditions. In this low workload and high task complexity condition, it was found that perceived workload positively predicts a deep approach to learning (see Table 7). The surface approach to learning does not relate significantly to perceived workload ( $\beta \mathrm{In}=$ 0.023, $t=0.257, p=0.798$ ).

The second research question focuses on the relation between task complexity and students' approaches to learning. The deep approach to learning is not significantly related to task complexity. The regression model that predicts a deep approach to learning excludes familiarity $(\beta \mathrm{In}=0.044, t=0.495, p=0.621)$, solutions $(\beta \mathrm{In}=-0.034, t=-0.379, p=0.705)$ and a lack of information $(\beta \operatorname{In}=-0.113, t=-1.288, p=0.200)$. The surface approach to learning does relate significantly to a lack of information. The regression model predicting the surface approach to learning shows that a lack of information is a positive predictor (see Table 8 ) while familiarity $(\beta \mathrm{In}=0.007, t=0.080, p=0.937)$ and solutions are excluded from the model $(\beta$ In $=-0.052, t=-0.591, p=0.556)$.

Low workload-low task complexity

Due to the results of the ANOVA which showed that groups A and B differ significantly for the surface approach in this low-low condition, the surface approach is analysed separately for both groups. First, the results for the first research question regarding the relation between perceived workload and students' approaches to learning will be presented. Results show no significant relation between perceived workload and students' approaches to learning. Perceived workload is excluded from the three regression models that predict the deep approach $(\beta \mathrm{In}=0.108, t=1.216, p=0.226)$, the surface approach of group A $(\beta$ In $=-0.036, t=-0.305, p=0.762)$ and the surface approach of group B $(\beta \mathrm{In}=0.030, t=0.239, p=0.812)$.

Like in the other research conditions, the influence of task complexity comes primarily from the factor "lack of information". A lack of information is the only significant

Table 6 High workload-low task complexity condition: stepwise regression for surface approach to learning

\begin{tabular}{lllllll}
\hline Model & $\begin{array}{l}\text { Unstandardised } \\
\text { coefficients }\end{array}$ & $\begin{array}{l}\text { Standardised } \\
\text { coefficients }\end{array}$ & $t$ & Sig. \\
\cline { 2 - 3 } & $\mathrm{B}$ & $\mathrm{Se}$ & $\beta$ & & \\
\hline $\begin{array}{l}\text { Lack of } \\
\text { information }\end{array}$ & 0.180 & 0.062 & 0.251 & 42.391 & 0.000 \\
\hline
\end{tabular}


Table 7 Low workload-high task complexity condition: stepwise regression for deep approach to learning

\begin{tabular}{|c|c|c|c|c|c|}
\hline \multirow[t]{2}{*}{ Model } & \multicolumn{2}{|c|}{$\begin{array}{l}\text { Unstandardised } \\
\text { coefficients }\end{array}$} & \multirow{2}{*}{$\begin{array}{l}\text { Standardised } \\
\text { coefficients } \\
\beta\end{array}$} & \multirow[t]{2}{*}{$t$} & \multirow[t]{2}{*}{ Sig. } \\
\hline & B & $\mathrm{Se}$ & & & \\
\hline (Constant) & 2.296 & 0.061 & & 37.607 & 0.000 \\
\hline Workload & 0.149 & 0.072 & 0.181 & 2.067 & 0.041 \\
\hline
\end{tabular}

(negative) predictor for a deep approach to learning (see Table 9). Familiarity $(\beta \mathrm{In}=0.016$, $t=0.178, p=0.859)$ and solutions $(\beta \mathrm{In}=0.074, t=0.842, p=0.402)$ are excluded from the model. This research condition also confirms the positive relation between a lack of information and a surface approach for both groups (see Table 10). The factor "solutions" was excluded as a predictor (group A: $\beta \mathrm{In}=0.67, t=0.564, p=0.575$; group $\mathrm{B}$ : $\beta \mathrm{In}=0.065$, $t=0.546, p=0.587)$. The factor familiarity was not a significant predictor for the surface approach of group A ( $\beta \mathrm{In}=-0.044, t=-0.369, p=0.714)$, but it was a significant predictor for group B (see Table 10).

Results across conditions

What can be concluded in general about the relations between perceived workload and task complexity with students' approaches to learning? We will revisit our two research questions with a specific focus on communalities and differences across the research conditions. Regarding the first research question, it was found that the relation between perceived workload and students' approaches to learning were not significant, except in the low workload-high task complexity condition. In this condition, perceived workload related significantly positively with a deep approach to learning. This can be explained by the distinction that Nijhuis et al. (2008) made between quantitative and qualitative workload. Besides the results of the factor analyses, the qualitative data also indicated that there are two sides to workload that seem to influence students' approaches to learning in a different way. On the one hand, students mentioned the large number of texts ("I found it was a heavy course in the sense that there were a lot of texts"), the size of the text ("Was it the size of the text? Yes, that was it, the task itself wasn't that bad"), the hours of work spent on the assignments ("I really invested a lot of effort and hours") and the pressure of time ("I invested a lot of time in it. There was a lot of pressure behind it"). These are all elements that refer to the quantitative side of the workload that seems to have a negative relationship with deep learning approaches. For example, a student who found the assignment where he/

Table 8 Low workload-high task complexity condition: stepwise regression for surface approach to learning

\begin{tabular}{lllllll}
\hline Model & $\begin{array}{l}\text { Unstandardised } \\
\text { coefficients }\end{array}$ & $\begin{array}{l}\text { Standardised } \\
\text { coefficients }\end{array}$ & $t$ & Sig. \\
\cline { 2 - 3 } & $\mathrm{B}$ & $\mathrm{Se}$ & $\beta$ & & & \\
\hline $\begin{array}{l}\text { Lack of } \\
\text { information }\end{array}$ & 0.166 & 0.067 & 0.216 & 39.333 & 0.000 \\
\hline
\end{tabular}


E. Kyndt et al.

Table 9 Low workload-low task complexity condition: stepwise regression for deep approach to learning

\begin{tabular}{lllllll}
\hline Model & $\begin{array}{l}\text { Unstandardised } \\
\text { coefficients }\end{array}$ & $\begin{array}{l}\text { Standardised } \\
\text { coefficients }\end{array}$ & $t$ & Sig. \\
\cline { 2 - 3 } & $\mathrm{B}$ & $\mathrm{Se}$ & $\beta$ & & \\
\hline $\begin{array}{l}\text { Lack of } \\
\text { information }\end{array}$ & -0.130 & 0.059 & -0.193 & & & \\
\hline
\end{tabular}

she had to interview a team member regarding the team effectiveness, to be the one with the highest workload in terms of hours and writing, approached this assignment in a surface manner: "... the theme was given, so I skimmed quickly through all the texts and searched for the theme in the titles and subtitles. I marked and read those sections and formulated questions about that". On the other hand, when talking about workload, students also referred to the qualitative aspect of workload, stating that an assignment was difficult ("The heaviest assignment for me was the one about the two perspectives. I found it a difficult text to analyse"), broad ("the observation was broader and included more elements") and had to be processed by oneself ("you had to learn a lot by yourself. During the lecture some things are explained, but there are a lot of texts that are not discussed in class"). In contrast, these qualitative aspects seemed to encourage a deeper approach to learning. "I started with reading the texts and making a scheme of the differences and communalities of the two perspectives. Next, I explained the assignment to the interviewee..." The lack of significant results to confirm our hypothesis, despite previous research results (e.g. Kember 2004; Ramsden 1992; Sand-Jecklin 2007), could be explained by the opposite influences of the different sides of the workload and the fact that the dominant influence (positive or negative) can differ for every student. In addition, it is likely that the low workload and high task complexity condition had a low quantitative workload and high qualitative workload since the operationalisation of workload focused on the quantity of workload. The positive relation between workload and a deep approach to learning in this specific condition seems to confirm the positive influence of the quality of workload. More research is needed on this distinction between quantitative and qualitative workload and their differential effects.

The second research question concerned the relationship between task complexity and students' approaches to learning. In this research, task complexity is represented by three factors: familiarity, solutions and lack of information. The results of the extreme conditions

Table 10 Low workload-low task complexity condition: stepwise regression for surface approach to learning

\begin{tabular}{lllllll}
\hline Group & Model & \multicolumn{2}{l}{ Unstandardised coefficients } & Standardised coefficients & $t$ & Sig. \\
\cline { 3 - 4 } & & B & Se & $\beta$ & 29.429 & 0.000 \\
\hline A & (Constant) & 1.882 & 0.064 & & 3.220 & 0.002 \\
& Lack of information & 0.219 & 0.068 & 0.378 & 33.015 & 0.000 \\
B & (Constant) & 2.206 & 0.067 & & 2.776 & 0.007 \\
& Lack of information & 0.285 & 0.103 & 0.330 & 2.085 & 0.041 \\
\hline
\end{tabular}


(high-high and low-low) show a significant negative relation between a deep approach to learning and a lack of information. Meaning that the greater the lack of information is perceived, the less prevalent the deep approach to learning will be. In the mixed conditions, this relation was not significant. For the surface approach, the positive relation with a lack of information was consistently significant in every research condition. The less information students had or could access, the more likely they were to adopt a surface approach regardless of the induced circumstances. The factor solutions did not show any significant relation with students' approaches to learning. For the factor familiarity, two significant relationships were found with students' approaches to learning. In the high-high condition, familiarity related positively to a deep approach to learning, while in the lowlow condition it also related positively, but this time to the surface approach to learning. This factor also has differential influences on students' approaches to learning when investigated under different induced conditions.

The qualitative data also offers important information about the perception of task complexity. When discussing the students' perceptions of task complexity, different elements of our definition of task complexity were brought up by the student. For the students a task was complex when they felt that they did not have enough information about the assignment itself or were given limited instructions, but also when they had the feeling they did not have enough substantive information or knowledge; "I thought it was difficult actually, because I had not read any texts" and "... the first assignment you get thrown in and in fact you don't know anything yet". The task was also perceived as complex when the content was experienced as difficult; "those characteristics were really difficult to explain" and when they had to link theory and practice; "I found it very theoretical and to apply that to practice, that was not easy". In addition, several elements that can be grouped as being a student's responsibility and choices when processing the assignment, were associated with the complexity of the task: "making choices", "laying emphasizes and using your own creativity", "interpreting", "forming an opinion" and "distinguishing important things". Prior research has argued that this responsibility could enhance student's deep approaches to learning (Wilson \& Fowler 2005). Finally, the unfamiliarity with a task ("I found the observation very complex, because we don't often do that") and the insecurity concerning the solution ("you also don't know if it will be good or not") were elements that could enhance the perceived task complexity. In general, the assignments with these characteristics were perceived as assignments that required understanding and insight into the theory, but this did not always lead to deeper strategies. Most students reported reading the appropriate texts or parts of the texts in order to solve the exercise, but most of them looked for elements they could use in their report, rather than attempting to understand the entire theory. The quantitative results showed a positive relationship between a lack of information and a surface approach to learning, but in the interviews there were no explicit quotes connecting these two variables. Nevertheless, the interviews made clear that the students were concerned with their grade. Consequently, the lack of information about the assignments and the feeling of not having enough knowledge could have made students insecure about the expectations of the lecturer and about their solutions which may have caused the increase in the use of surface approaches.

\section{Conclusion and discussion}

The results of this study show that the lack of information is a discouraging factor when trying to induce a deep learning approach. It consistently increases students' 
surface approaches to learning, regardless of the induced workload and task complexity of the assignment. In addition, in extreme conditions (workload and task complexity both high or low), the deep approach to learning relates negatively to a lack of information. The higher the perceived lack of information provided to students, the less they adopt a deep approach to learning. Since deep and surface approaches to learning are not dichotomic variables but can be placed on a continuum (Schmeck 1988), one would expect that, in line with the results regarding surface approaches, the deep approach to learning would relate significantly negatively to a lack of information in every condition and not only in the extreme conditions. This continuum is shown by the significant negative correlations between deep and surface approaches to learning; however, it can be noticed that this negative correlations are stronger in the extreme conditions, than they are in the mixed conditions. These mixed conditions seem to make the differences in the use of surface and deep approach smaller, explaining why a deep approach to learning is not significantly related to a lack of information while the surface approach to learning is. It appears that in these mixed conditions workload and task complexity compensate each other's influence.

Perkins (1991) stated that the gap between the entry behaviour of a student and what is expected of that student within a student-centred setting may be too big. The results concerning a lack of information support this statement in that the gap Perkins (1991) speaks about can be created (among other things) by a lack of information. A studentcentred setting demands more initiative and autonomy on the part of the students in comparison to a teacher-centred setting, leaving them with all kinds of questions and insecurities. Consequently, when students have the feeling that they do not have enough information or knowledge to complete the exercise or to solve the problem, they tend to resort to a more surface approach to learning.

Moreover, this research shows that familiarity is a positive predictor of a deep approach to learning in the high workload-high task complexity condition. Looking back at previous studies, several studies confirmed the positive influence of studentcentred learning environments on deep approaches to learning (e.g. Tiwari et al. 2006; Wilson \& Fowler 2005). However, other studies have observed increases in surface approaches in such student-centred learning environments (e.g. Gijbels et al. 2005; Nijhuis et al. 2005; Segers et al. 2006; Struyven et al. 2006). Our findings provide an explanation for these results; many of the learning environments used in these studies (such as PBL) are clearly high workload-high complexity situations (Hung 2009); moreover, they were investigated with students who experienced this new learning environment for the first time which led to an unfamiliar situation for these students. As a consequence, these learning environments did not enhance students' deep approaches to learning. Another remarkable finding is that familiarity influences students' approaches to learning differently under different conditions. In the high-high conditions, it positively influences a deep approach to learning, but under the low-low condition, it positively influences a surface approach to learning. Apparently, when the circumstances are considered "less demanding", familiarity contributes negatively to students' approaches to learning.

The results concerning the influence of workload were not as hypothesised. A possible explanation is that there are two sides to perceived workload. On the one hand you have the quantity of workload which is expected to reveal a negative influence on approaches to learning (e.g. Kember 2004; Ramsden 1992; Sand-Jecklin 2007). On the 
other hand, however, both the factor analysis and the qualitative data show a more qualitative aspect of workload. This qualitative side could have the potential to challenge students and give them a feeling of fulfilment, leading to a positive influence on approaches to learning.

This research has arrived at some interesting conclusions; however, certain remarks can be made. First, it needs to be mentioned that this research was conducted over a rather short period of one semester (4 months). The duration of the intervention could have had an influence on the changes or the lack of them regarding students' approaches to learning. Furthermore, the sample was sufficiently large to conduct the analyses but nevertheless limited, the sample consisted almost entirely out of females which is common for a sample of educational sciences students; however, former research remains inconclusive about the influence of gender on approaches to learning (Gijbels et al. 2005; Zeegers 2004). Moreover, this sample consisted of students in educational sciences and one should bear in mind that prior research has shown that students from different disciplines can differ significantly from each other regarding learning approaches (Kember et al. 2008; Lonka \& Lindblom-Ylänne 1996; Smith \& Miller 2005; Valk \& Marandi 2005). Studies with students from other disciplines or (quasi-)experiments over a longer period of time could add interesting findings to the body of knowledge. Finally, the instrument that measured perceived task complexity could need improvements. The factor analysis divided task complexity into three factors with a limited number of items. Several other factor solutions were examined, but this three factor solution appeared the most suited in this research, since all three factors are reliable and contributed a substantial portion of the explained variance $(>9.5 \%)$. From a content point of view, this solution corresponded the best with the definition and the qualitative data in this study. However, it has to be recognised that two questions in a factor are quite problematic when constructing a subscale, however, the high loadings give a clear indication that they go in tandem. Future research would benefit from a more broadly validated measure of task complexity.

Further, when starting this research study, task complexity and workload were treated as two separate variables that both had an influence on students' approaches to learning. When creating our research conditions we operationalised the variables as separately as possible, in essence by focusing on the aspects that distinguished both variables. Variations in workload where operationalised as mentioned by focusing on the quantitative aspects of the assignment; hours invested and required output. While for the induction of task complexity the variation was performed on the characteristics familiarity, multiple paths to a solution and an uncertainty of outcome. Students were asked to apply the theories from the course to actual professional practice. This application of theory into practice is something that is rather unfamiliar for novice university students. In addition, there are multiple ways of interpreting situations and applying theory. Since professional practice seldom corresponds entirely with a theoretical model, students were in general uncertain about their solution. The subjective task complexity instrument focused on these aspects; however, the workload measure did not focus on the quantitative aspect of workload. We chose to work with an existing and validated questionnaire which was designed to measure the entire concept of workload as defined in the theoretical background. Looking back on this study and its results, we can notice that the results were the clearest in the extreme conditions and that it is very difficult to distinguish between workload and task complexity for students, especially in the mixed conditions as can be seen in the a posteriori manipulation check. As 
consequence, it is also very difficult to measure the perceptions both constructs separately. This raises the question as to how "separate" these constructs actually are in practice? Our results seem to indicate that an overlap exists between both variables and that they compensate or reinforce each other's influence. A critical reflection about what constitutes and distinguishes workload and task complexity is needed, as well as a critical reflection on the measurement instruments and methods that are able to distinguish between these task characteristics.

This research has however shown that investigating the relation between two variables under different conditions can lead to a deeper insight into the nature of the relationships. Some influences are consistent across different conditions, such as a lack of information in this study. While other variables act differently under different circumstances or different individuals, for example the factor familiarity or perceived workload. We believe that this approach can be fruitful for future research.

\section{Appendix 1. Items and factor loadings with regard to perceived workload and task complexity}

Table 11 Rotated factor matrix (loadings less than 0.35 omitted)

\begin{tabular}{|c|c|c|c|c|}
\hline & \multicolumn{4}{|l|}{ Factor } \\
\hline & 1 & 2 & 3 & 4 \\
\hline $\begin{array}{l}\text { WL1: Mental demand: how mentally demanding was this task? } \\
\text { How much mental activity (for example: thinking, deciding, } \\
\text { calculating, remembering, searching, ...) was required? }\end{array}$ & 0.852 & & & \\
\hline WL2: Physical demands: how physically demanding was this task? & 0.498 & & & \\
\hline $\begin{array}{l}\text { WL3: Temporal demands: how "rushed" was your work pace for } \\
\text { this assignment? How much time pressure did you experience? }\end{array}$ & 0.677 & & & \\
\hline $\begin{array}{l}\text { WL4: Effort: how hard did you have to work to obtain your } \\
\text { level of achievement? }\end{array}$ & 0.804 & & & \\
\hline $\begin{array}{l}\text { WL5: Frustration: how insecure, discouraged, irritated, stressed or } \\
\text { annoyed did you feel while undertaking this task? }\end{array}$ & 0.703 & & & \\
\hline WL6: I found it a hard task. & 0.876 & & & \\
\hline $\begin{array}{l}\text { TC1: I've undertaken similar tasks in the past. I was familiar with } \\
\text { the design of the task. }\end{array}$ & & 0.922 & & \\
\hline $\begin{array}{l}\text { TC2: I had too little information, information resources and aids } \\
\text { at my disposal while completing this task. }\end{array}$ & & & & 0.741 \\
\hline $\begin{array}{l}\text { TC3: There were multiple possible ways to come to a solution } \\
\text { for this task. }\end{array}$ & & & 0.998 & \\
\hline TC4: There remains an insecurity about the solution to this task. & 0.561 & & & \\
\hline TC5: I found it a difficult task. & 0.869 & & & \\
\hline $\begin{array}{l}\text { TC6: The task was not completely unknown to me, I've } \\
\text { undertaken similar tasks in the past. }\end{array}$ & & 0.983 & & \\
\hline $\begin{array}{l}\text { TC7: I could have solved the task in a different way than the } \\
\text { way I have used. }\end{array}$ & & & 0.733 & \\
\hline TC8: I found it a complicated task. & 0.731 & & & \\
\hline TC9: The information resources were difficult to access. & & & & 0.675 \\
\hline
\end{tabular}

Extraction method maximum likelihood, rotation method Varimax with Kaiser Normalisation 


\section{Appendix 2. Results correlations}

Table 12 Results correlations

\begin{tabular}{|c|c|c|c|c|c|c|}
\hline & Deep approach & Surface approach & & Workload & Familiarity & Solutions \\
\hline \multicolumn{7}{|c|}{ High workload-high task complexity } \\
\hline Surface approach & $-0.317 * *$ & & & & & \\
\hline Workload & 0.032 & -0.064 & & & & \\
\hline Familiarity & 0.141 & -0.041 & & 0.086 & & \\
\hline Solutions & 0.072 & -0.079 & & -0.013 & -0.086 & \\
\hline Lack of information & $-0.252 * *$ & $0.207 *$ & & 0.044 & 0.121 & -0.039 \\
\hline \multicolumn{7}{|c|}{ High workload-low task complexity } \\
\hline Surface approach & $-0.184 *$ & & & & & \\
\hline Workload & 0.096 & 0.009 & & & & \\
\hline Familiarity & 0.058 & 0.161 & & -0.055 & & \\
\hline Solutions & 0.059 & 0.105 & & 0.163 & -0.152 & \\
\hline Lack of information & -0.087 & $0.251^{* *}$ & & $0.183^{*}$ & 0.044 & 0.044 \\
\hline \multicolumn{7}{|c|}{ Low workload-high task complexity } \\
\hline Surface approach & $-0.285 * *$ & & & & & \\
\hline Workload & $0.181 *$ & 0.038 & & & & \\
\hline Familiarity & 0.018 & -0.005 & & -0.137 & & \\
\hline Solutions & 0.004 & -0.026 & & $0.203 *$ & 0.135 & \\
\hline Lack of information & -0.099 & $0.216^{*}$ & & 0.073 & -0.056 & 0.116 \\
\hline \multicolumn{7}{|c|}{ Low workload-low task complexity } \\
\hline Surface approach & A: -0.192 & A & $\mathrm{B}$ & & & \\
\hline & B: $-0.323^{* *}$ & & & & & \\
\hline Workload & 0.068 & -0.036 & 0.029 & & & \\
\hline Familiarity & 0.033 & -0.055 & 0.222 & $-0.211^{*}$ & & \\
\hline Solutions & 0.093 & 0.065 & 0.071 & $-0.341 * *$ & 0.095 & \\
\hline Lack of information & $-0.193 *$ & $0.378 * *$ & $0.311 *$ & $0.191 *$ & -0.091 & -0.100 \\
\hline
\end{tabular}

$* p<0.05 ; * * p<0.01$

\section{References}

Argyris, C., \& Schön, D. (1978). Organizational learning: A theory of action perspective, reading. MA: Addison-Wesley.

Baeten, M., Kyndt, E., Struyven, K., \& Dochy, F. (2010). Using student-centered learning environments to stimulate deep approaches to learning: factors encouraging or discouraging their effectiveness. Educational Research Review, 5(3), 243-260.

Biggs, J.B. (1987). Study Process Questionnaire Manual. Melbourne: Australian Council for Educational Research.

Biggs, J. (2001). Enhancing learning: A matter of style or approach? In R. J. Sternberg \& L. Zhang (Eds.), Perspectives on thinking, learning, and cognitive styles (pp. 73-102). Mahwah: Lawrence Erlbaum Associates.

Biggs, J., Kember, D., \& Leung, D. Y. P. (2001). The revised two-factor study process questionnaire: R-SPQ2F. The British Journal of Educational Psychology, 71, 133-149.

Boyatzis, R. E., Stubbs, E. C., \& Taylor, S. N. (2002). Learning cognitive and emotional intelligence competences through graduate management education. Academy of Management Journal on Learning and Education, 1(2), 150-162. 
Braarud, P. (2001). Subjective task complexity and subjective workload: Criterion validity for complex team tasks. International Journal of Cognitive Ergonomics, 5(3), 261-273.

Campbell, D. J. (1988). Task complexity: A review and analysis. Academy of Management Review, 13(1), 40-52.

Campbell, J., Smith, D., Boulton-Lewis, G., Brownlee, J., Burnett, P. C., Carrington, S., et al. (2001). Students' perception of teaching and learning: The influence of students' approaches to learning and teachers' approaching to teaching. Teachers and Teaching: Theory and Practice, 7(2), 173-187.

Decuyper, S., Dochy, F., \& Van den Bossche, P. (2010). Grasping the dynamic complexity of team learning: An integrative model for effective team learning in organisations. Educational Research Review, 5(2), 111-133.

Diseth, A., Pallesen, S., Hovland, A., \& Larsen, S. (2006). Course experiences, approaches to learning and academic achievement. Education and Training, 48(2-3), 156-169.

Entwistle, N. J. (1991). Approaches to learning and perceptions of the learning environment. Introduction to the special issue. Higher Education, 22, 201-204.

Entwistle, N. J., \& Ramsden, P. (1983). Understanding student learning. London: Croom Helm.

Entwistle, N., McCune, V., \& Walker, P. (2001). Conceptions, styles, and approaches within higher education: Analytical abstractions and everyday experience. In R. J. Sternberg \& L.-F. Zhang (Eds.), Perspectives on cognitive, learning and thinking styles (pp. 103-136). New Jersey: Lawrence Erlbaum Associates.

Gijbels, D. (2007). The road to hell: Attempts to enhance students learning approaches. PbPr Conference EARLI, Maastricht, 15 November 2007.

Gijbels, D., Van de Watering, G., Dochy, F., \& Van den Bossche, P. (2005). The relationship between students' approaches to learning and the assessment of learning outcomes. European Journal of Psychology of Education, 20(4), 327-341.

Gijbels, D., Segers, M., \& Struyf, E. (2008). Constructivist learning environments and the (im)possibility to change students' perceptions of assessment demands and approaches to learning. Instructional Science, 36(5-6), 431-443.

Glouberman, S., \& Zimmerman, B. (2002). Complicated and complex systems: What would successful reform of Medicare look like? Discussion Paper, Commission on the Future of health care in Canada. Retrieved on January 04, 2008 from http://www.healthandeverything.org/files/Glouberman_E.pdf

Haerem, T., \& Rau, D. (2007). The influence of degree of expertise and objective task complexity on perceived task complexity and performance. The Journal of Applied Psychology, 92(5), 1320-1331.

Hambleton, R. K. (1994). Guidelines for adapting educational and psychological tests: A progress report. European Journal of Psychological Assessment, 10, 229-244.

Hart, S. G., \& Staveland, L. E. (1988). Development of NASA-TLX (Task Load Index): Results of empirical and theoretical research. In P. A. Hancock \& N. Meshkati (Eds.), Human mental workload (pp. 139183). Amsterdam: North-Holland.

Hounsell, D. (1984). Learning and essay-writing. In F. Marton, D. Hounsell, \& N. Entwistle (Eds.), The experience of learning. Implications for teaching and studying in higher education (pp. 103-123). Edinburgh: Scottish Academic Press.

Hu, L., \& Bentler, P. M. (1999). Cut-off criteria for fit indexes in covariance structure analysis: Conventional criteria versus new alternations. Structural Equation Modelling, 6, 1-55.

Hung, W. (2009). The 9-step problem design process for problem-based learning: Application of the 3C3R model. Educational Research Review, 4(2), 118-141.

Karangiannopoulou, E., \& Christodoulides, P. (2005). The impact of Greek university students' perceptions of their learning environment on approaches to studying and academic outcomes. International Journal of Educational Research, 43, 329-350.

Kember, D. (2004). Interpreting student workload and the factors which shape students' perceptions of their workload. Studies in Higher Education, 29(2), 165-184.

Kember, D., \& Leung, D. (1998). Influences upon students' perceptions of workload. Educational Psychology, 18(3), 293-307.

Kember, D., Charlesworth, M., Dabies, H., MacKay, J., \& Stott, V. (1997). Evaluating the effectiveness of educational innovations: Using the study process questionnaire to show that meaningful learning occurs. Studies in Educational Evaluation, 23(2), 141-157.

Kember, D., Leung, D. Y. P., \& McNaught, C. (2008). A workshop activity to demonstrate that approaches to learning are influenced by the teaching and learning environment. Active Learning in Higher Education, $9,43-56$.

Lizzio, A., Wilson, K., \& Simons, R. (2002). University students' perceptions of the learning environment and academic outcomes: Implications for theory and practice. Studies in Higher Education, 27, $27-52$.

Lonka, K., \& Lindblom-Ylänne, S. (1996). Epistemologies, conceptions of learning, and study practices in medicine and psychology. Higher Education, 31, 5-24.

Mangos, P. M., \& Steele-Johnson, D. (2001). The role of subjective task complexity in goal orientation, selfefficacy, and performance relations. Human Performance, 14(2), 169-186. 
Marton, F., \& Säljö, R. (1997). Approaches to learning. In F. Marton, D. Hounsell, \& N. Entwistle (Eds.), The experience of learning. Implications for teaching and studying in higher education (pp. 39-58). Edinburgh: Scottish Academic Press.

Maynard, D. C., \& Hakel, M. D. (1997). Effects of objective and subjective task complexity on performance. Human Performance, 10(4), 303-330.

Mennin, S. (2007). Small-group problem-based learning as a complex adaptive system. Teaching and Teacher Education, 23, 303-313.

Neilsen, A. C. (2000): Employer satisfaction with graduate skills: Research report. Evaluations and investigation programme. Canberra: DETYA, Higher Education Division. Retrieved on December 10, 2007 on http://www.dest.gov.au/archive/highered/eippubs/eip99-7/eip99_7pdf.pdf.

Nijhuis, J., Segers, M., \& Gijselaers, W. (2005). Influence of redesigning a learning environment on student perceptions and learning strategies. Learning Environments Research, 8, 67-93.

Nijhuis, J., Segers, M., \& Gijselaers, W. (2008). The extent of variability in learning strategies and students' perceptions of the learning environment. Learning and Instruction, 18(2), 121-134.

Perkins, D. N. (1991). What constructivism demands of the learner. Educational Technology, 31(9), 19-21.

Prosser, M., \& Trigwell, K. (1999). Understanding learning and teaching: The experience in higher education. Buckingham: The Society for Research into Higher Education.

Ramsden, P. (1992). Learning to teach in higher education. London: Kogan Page.

Sadlo, G., \& Richardson, J. (2003). Approaches to studying and perceptions of the academic environment in students following problem-based and subject based curricula. Higher Education Research and Development, 22(3), 253-274.

Salthouse, T. A. (1992). Why do adult age differences increase with task complexity? Developmental Psychology, 28(5), 905-918.

Sand-Jecklin, K. (2007). The impact of active/cooperative instruction on beginning nursing student learning strategy preference. Nurse Education Today, 27, 474-480.

Schmeck, R. R. (1988). Strategies and styles of learning. An integration of varied perspectives. In R. R. Schmeck (Ed.), Learning strategies and learning styles (pp. 317-347). New York: Plenum Press.

Segers, M., Nijhuis, J., \& Gijselaers, W. (2006). Redesigning a learning and assessment environment: The influence on students' perceptions of assessment demands and their learning strategies. Studies in Educational Evaluation, 32, 223-242.

Smith, S. N., \& Miller, R. J. (2005). Learning approaches: Examination type, discipline of study, and gender. Educational Psychology, 25(1), 43-53.

Stahl, E., Pieschl, S., \& Bromme, R. (2006). Task complexity, epistemological beliefs and metacognitive calibration: An exploratory study. Journal of Educational Computing Research, 35(4), 319-338.

Stes, A., De Maeyer, S., \& Van Petegem, P. (2008). Students'study approaches: a study into the validity and reliability of a Dutch version of the $R-S P Q-2 F$. European learning styles information network, 13th annual conference. Gent, 23-25 juni 2008.

Struyven, K., Dochy, F., Janssens, S., \& Gielen, S. (2006). On the dynamics of students' approaches to learning: The effects of the teaching/learning environment. Learning and Instruction, 16, 279-294.

Szafran, R. F. (2001). The effect of academic load on success for new college students: Is lighter better? Research in Higher Education, 42(1), 27-50.

Tiwari, A., Chan, S., Wong, E., Wong, D., Chui, C., Wong, A., et al. (2006). The effect of problem-based learning on students' approaches to learning in the context of clinical nursing education. Nurse Education Today, 26, 430-438.

Trigwell, K., \& Prosser, M. (1991). Improving the quality of student learning: The influence of learning context and student approaches to learning on learning outcomes. Higher Education, 22, $251-266$.

Tynjälä, P. (1999). Towards expert knowledge? A comparison between a constructivist and a traditional learning environment in the university. International Journal of Educational Research, 31(5), 357442 .

Valk, A., \& Marandi, T. (2005). How to support deep learning at a university? In: F.E.H. Tay, T.S Chuan, \& S.Han-Ming (Eds.), Proceeding of the International Conference on Education 2005. National University of Singapore.

Wilson, K., \& Fowler, J. (2005). Assessing the impact of learning environments on students approaches to learning: Comparing conventional and action learning designs. Assessment and Evaluation in Higher Education, 30(1), 87-101.

Wilson, K. L., Lizzio, A., \& Ramsden, P. (1997). The development, validation and appreciation of the course experience questionnaire. Studies in Higher Education, 22, 33-53.

Zeegers, P. (2004). Student learning in higher education: A path analysis of academic achievement in science. Higher Education Research and Development, 23(1), 35-56. 


\section{Eva Kyndt.}

Current themes of research:

Approaches to learning. Higher education. Professional learning. Learning climate.

Most relevant publication in the field of Psychology of Education:

Baeten, M.*, Kyndt, E*., Struyven, K., \& Dochy, F. (2010). Using student-centred learning environments to stimulate deep approaches to learning: factors encouraging or discouraging their effectiveness. Educational Research Review, 5(3), 243-260. (*Both authors are equally considered first author)

Kyndt, E., Dochy, F., Cascallar, E., \& Struyven, K. (2011, Accepted). The direct and indirect effect of motivation for learning on students' approaches to learning, through perceptions of workload and task complexity. Higher Education Research \& Development.

Kyndt, E., Dochy, F., Michielsen, M., \& Moeyaert, B. (2009). Employee retention: organisational and personal perspectives. Vocations and Learning, 2(3), 195-215.

Kyndt, E., Dochy, F., \& Nijs, H. (2009). Learning conditions for non-formal and informal workplace learning. Journal of Workplace Learning, 21(5), 369-383.

\section{Filip Dochy.}

Current themes of research:

Assessment. Learning in professions. Team learning. Lifelong learning. Corporate learning.

Most relevant publication in the field of Psychology of Education:

Dochy, F., Segers, M., Van den Bossche, P., \& Gijbels, D. (2003). Effects of problem-based learning: a metaanalysis. Learning and instruction, 13, 533-568.

Birenbaum, M., Breuer, K., Cascallar, E., Dochy, F., Dori, Y., Ridgway, J., Wiesemes, R., \& Nickmans, G. (2006). A learning integrated assessment system. Educational Research Review, 1, 61-67.

Decuyper, S., Dochy, F., \& Van den Bossche, P. (2010). Grasping the dynamic complexity of team learning: An integrative model for effective team learning in organisations. Educational Research Review, 5(2), 111-133.

Sierens, E., Vansteenkiste, M., Goossens, L., Soenens, B., Soenens, B., \& Dochy, F. (2009). The synergistic relationship of perceived autonomy support and structure in the prediction of self-regulated learning. British Journal of Educational Psychology, 79(1), 57-68.

Dochy, F., Kyndt, E., Baeten, M., Pottier, S., \& Veestraeten, M. (2009). The effects of different standard setting methods and the composition of borderline groups: a study within a law curriculum. Studies in Educational Evaluation, 35(4), 174-182.

\section{Katrien Struyven.}

Current themes of research:

Teaching methods and instruction. Assessment. Competences in education / Competence-based education. Teacher education.

Most relevant publication in the field of Psychology of Education:

Struyven, K., \& De Meys, M. (2010). Competence-based teacher education: illusion or reality? An assessment of the implementation status in Flanders from teachers' and students' points of view. Teaching and Teacher Education, 26, 1495-1510.

Struyven, K., Dochy, F., \& Janssens, S. (2010). Teach as you preach: the effects of student-centred versus lecture-based teaching on student teachers' approaches to teaching. European Journal of Teacher Education, 33(1), 43-64. 
Struyven, K., Dochy, F., \& Janssens, S. (2008). The effects of hands-on experiences on students' preferences of assessment methods. Journal of Teacher Education, 59(1), 69-88.

Struyven, K., Dochy, F., \& Janssens, S. (2008). Students' likes and dislikes regarding student-activating and lecture-based educational settings: criteria that matter. European Journal of Psychology of Education, 23 (3), 295-317.

Struyven, K., Dochy, F., Janssens, S., \& Gielen, S. (2006). On the dynamics of students' approaches to learning: the effects of the learning/teaching environment. Learning and Instruction), 16(4), 279-294.

\section{Eduardo Cascallar.}

Current themes of research:

Assessment. Predictive systems. Cognitive processes.

Most relevant publication in the field of Psychology of Education:

Cascallar, E. C., Boekaerts, M., \& Costigan, T. E. (2006). Assessment in the evaluation of self-regulation as a process. Educational Psychology Review, 18(3), 297-306.

Boekaerts, M. \& Cascallar, E.C. (2006). How far have we moved toward the integration of theory and practice in self-regulation. Educational Psychology Review, 18(3), 199-210.

Birenbaum, M., Breuer, K., Cascallar, E., Dochy, F., Dori, Y., \& Ridgway, J. (2006) A learning Integrated Assessment System. Educational Research Review, 1(1), 61-67.

Cascallar, E. C., \& Musso, M. F. (2008). Classificatory stream analysis in the prediction of expected reading readiness: understanding student performance. International Journal of Psychology, 43(3/4), 231.

Musso, M. F., \& Cascallar, E. C. (2009). New approaches for improved quality in educational assessments: using automated predictive systems in reading and mathematics. Journal of Problems of Education in the 21st Century, 17, 134-151. 